\title{
Spatial interactions of employment in European labour markets
}

\author{
Laura Helena KIVI*, Tiiu PAAS**
}

\begin{abstract}
The paper investigates spatial interactions in European labour markets putting emphasis on the resilience of possible interactions during the period 2004-2018. The study is conducted based on employment data of the Eurostat NUTS 2 level regions by using several types of spatial econometric models and following theoretical assumptions that employment rate in one region is affected by employment rate changes and unobserved shocks in other regions. Spatial interactions in employment rates have slightly risen since the Eastern enlargement of the European Union in 2004 and continued to increase during the previous financial crisis. Since 2010, spatial dependence has been comparatively stable, having a slight tendency to decrease during the recent years. The results indicate that spatial interactions of regional labour markets are resilient to economic downturns, thus confirming the importance of close coordination between regions while also developing labour market and regional policy measures during different types of crises.
\end{abstract}

Keywords: regional labour markets, spatial effects, spatial econometrics, resilience, regional cooperation

\section{Introduction}

Since the seminal work by Blanchard and Katz (1992), which indicated that labour mobility is one of the decisive mechanisms in response to shocks in decreasing labour market disparities between regions, regional labour market interactions have received more attention. An important contribution to the field was made by Halleck Vega and Elhorst (2014), who expanded the model developed by Blanchard and Katz (1992) by including spatial interactions and found that the majority of the spillover effects between Western European regions are highly

* Laura Helena KIVI is PhD candidate at the University of Tartu, Estonia and researcher at the Estonian Center for Applied Research (CentAR), Tallinn, Estonia; e-mail: laura.helena.kivi@ut.ee.

***Tiiu PAAS is a Professor at the University of Tartu, Estonia; e-mail: tiiu.paas@ut.ee. 
significant. Significant spatial interactions have also been shown for one country datasets (e.g. Aragon et al., 2003; Filiztekin, 2009; Halleck Vega and Elhorst, 2016; Semerikova, 2015).

Thus, theoretical considerations and previous empirical evidence show that in looking for new development opportunities and responding to shocks, neither employers, nor employees are restricted to the activities in their residence region. They consider broader space and development possibilities by focusing on crossregional as well as cross-border mobility and cooperation. Consequently, analysing labour market developments without considering spatial interactions can lead to misleading results for elaborating proper policy proposals (Anselin, 1988; Anselin et al., 1996).

Despite numerous studies on regional labour market developments, there is still a gap in analysing types and intensity of spatial interactions. The previous empirical literature on spatial dependence in labour markets has mainly analysed regional interactions in unemployment rates and confirms significant positive spatial interactions (Badinger and Url, 2002; Beyer and Stemmer, 2016; Elhorst, 2003; Kondo, 2015; Niebuhr, 2003). While unemployment and employment indicators are related to the overall equilibrium in the labour market, their spatial interactions differ in terms of intensity and type of interaction. The evidence focused on employment indicators has found mixed results in terms of the sign of the dominating effects (Brada et al., 2021; Clark and Bayley, 2018; Lewis et al., 2011; Mayor and López, 2008; Pavlyuk, 2011). It remains unclear whether cooperation effects, which lead to positive spatial dependence, or competition effects, characterised by negative dependence of regional labour markets, dominate.

Following the above mentioned considerations, the paper aims to investigate spatial interactions in European labour markets by putting emphasis on the resilience of possible interactions during the period 2004-2018. The study contributes to the literature by estimating the dominating type of spatial interactions and by assessing the intensity and dynamics of these interactions over time, including across economic cycles and EU integration process.

The empirical part of the study relies on the data of European NUTS ${ }^{1} 2$ regions estimating spatial econometric models such as spatial lag model (SLM), spatial error model (SEM), and spatial autoregressive model with autoregressive disturbances (SARAR). Spatial interaction effects are calculated and analysed as spatial coefficients. When analysing spatial interactions in European labour markets, several cofounding factors that characterize regions' human capital, demography, industrial composition and country-specific conditions are considered. To check for

\footnotetext{
${ }^{1}$ NUTS - the Nomenclature of Territorial Units for Statistics implemented by Eurostat. The NUTS 2021 classification, that will be valid from 1 January 2021, lists 104 regions at NUTS 1, 283 regions at NUTS 2 and 1345 regions at NUTS 3 level (European Commission, 2020).
} 
the robustness of the results over time, models for different years within the 20042018 period are estimated.

The estimation results are robust. The findings show that spatial interactions across regional labour markets exist, thus indicating that regional labour markets in Europe cluster in space. Changes in employment rate in one region are directly affected by labour market developments and shocks in other regions. Cooperation effects dominate over competition effects and this evidence holds across economic cycles. Spatial interactions play a remarkable role in business activities and development of labour markets indicating the necessity to implement coordinated policy measures.

The rest of the paper is organized as follows. Section 2 gives a short overview of literature on analysing possible spatial interactions of regional labour markets. Section 3 introduces data and implemented econometric methods. Section 4 presents and discusses empirical results. Finally, section 5 concludes with a focus on some possible policy implications.

\section{Literature review}

Employment and unemployment rates are key aggregates that characterize regional labour markets. Employment indicators characterize the size and economic and demographic structure of regional labour markets. Unemployment rates reflect labour market disequilibrium, indicating that labour demand and supply are not fully balanced. The most important factor among socio-economic and demographic conditions affecting the achievement of labour market equilibrium are wages. The achievement of equilibrium in regional labour markets is also considerably influenced by spatial interactions between regions (see e.g. Badinger and Url, 2002, who report that around one-fifth of the variation in regional unemployment rates can be accounted to spatial effects). Both sides of a labour market, employers and employees, are flexible in space and can thereby change regional labour supply and demand. In the long run, regional unemployment rates should adjust towards the nation-wide mean (Aragon et al., 2003).

Previous empirical studies on spatial interactions of the regional labour market have mainly been focused on examining spatial dependence in the case of unemployment rates. Empirical evidence shows that there is mainly positive spatial dependence in unemployment rates. Regions with a high/low unemployment rate are surrounded by regions with a similar labour market situation. These empirical results have been valid in the case of several countries, e.g. the UK (Molho, 1995; Patacchini and Zenou, 2007), Spain (López-Bazo et al., 2002), France (Aragon et al., 2003), Italy (Cracolici et al., 2007), Turkey (Filiztekin, 2009), Japan (Kondo, 2015), Germany (Semerikova, 2015) and Colombia (Diaz, 2016).

Very few studies have been conducted for exploring spatial dependence in the case of employment rates and the results of these studies are mixed. Some studies 
have found that employment rates are negatively dependent on each other (Mayor and López, 2008; Pavlyuk, 2011), while others indicate positive spatial dependence (Brada et al., 2021; Lewis et al., 2011).

Spatial dependence between regional labour markets results from different interaction mechanisms. It can be a sign of commuting and migration flows across regions (Patacchini and Zenou, 2007), agglomeration and knowledge spillovers (Autant-Bernard and LeSage, 2011) or social network peer effects (Cingano and Rosolia, 2012). The interaction of these factors can either lead to positive or negative spatial dependence.

Employment rates are negatively dependent on each other, if employment rate in region $i$ increases, then employment rate in region $j$ decreases. This negative relationship can occur when expanding some sectors or industries in one region drives the companies operating in the same sector, but in another region, out of the market. Another explanation of the negative dependence is provided if one region pulls the labour force from another region, i.e. workers from region $i$ migrate to region $j$, lowering the number of the employed in region $i$. As these interaction patterns can be interpreted as possible competition among regions, they are referred to as competition effects in the following text.

Positive dependence of employment rates occurs when an increase in region $i$ is incorporated with an increase in employment in region $j$. Geographically close regions can have closer relations, while there are more possibilities for face-to-face meetings, which can lead to positive knowledge spillovers between the firms (Autant-Bernard and LeSage, 2011). The positive spatial dependence can also occur due to commuting, expanding businesses to neighbouring regions and agglomeration. To refer to these different types of mechanisms, the term cooperation effects is used throughout the study.

The mixed results of previous studies on the dominating type of spatial dependence might be partly explained by the different size of regions as well as by country and region-specific conditions and economic cycles, including several types of crises. For instance, Pavlyuk (2011) studied Latvian regional employment rates and recognised that the spatial dependence is negative and that, consequently, there is competition for labour resources among the regions. It should be noted that this study uses geographically relatively small regions, which might also affect the results. Lewis et al. (2011) focus their analysis on spatial dependence in the manufacturing sector in the counties of South Carolina. Changes in manufacturing employment are found to have a positive relationship with employment changes in the neighbouring counties. Here, the sign of the relationship is likely to result from some positive cooperation effects among industries in different regions. Mayor and López (2008) use the employment data for NUTS 3 regions in Spain and, contrary to Lewis et al. (2011), report the effects of the spatial dependence of employment change to be slightly negative. Economic cycles and several political and socioeconomic events are also related to changes in regional employment and their 
possible spatial interactions through channels like demographic structure of population, human capital, industrial structure, institutional settings, etc. (Clark and Bayley, 2018). Brada et al. (2021) use the data from the 2008 financial crisis and its recovery period and determine that changes in the non-agricultural employment have strong positive spillovers across regions in Central and Eastern Europe. They find that the changes in the industry structure are one of the main channels of spatial spillovers.

The mixed results of previous studies may also be partly due to the variety of methods implemented for analysing regional labour markets and for assessing spatial interactions. The combined implementation of several spatial econometric models creates additional possibilities for identifying proper types of spatial interactions and, thereby, for answering the questions whether regional cooperation or competition effects dominate in the European regional labour markets. Besides determining the type of dominating effects, the focus of this paper is on the dynamics of these effects and their resilience to crisis and economic recovery.

\section{Empirical strategy}

The empirical part of the study relies on the data of NUTS 2 regions' employment indicators in Europe. The NUTS classification is a system set up by Eurostat that establishes a hierarchy of three NUTS levels for each EU member state. The NUTS 2 level is defined as basic regions for the application of regional policies (European Commission, 2020). ${ }^{2}$

As shown in Figure 1, the indicators for Europe's NUTS 2 regions cluster in the space within national borders (e.g. Spain, France) as well as across borders. For instance, the regions in the south of Germany have similar employment rate values with their neighbours' across the border in Switzerland and Austria. The similarities in neighbouring regions' indicators can be partially explained by spatial interactions between labour markets, and partially by several socio-demographic and economic factors (e.g. demographic structure of the population, industrial structure, human capital).

${ }^{2}$ Countries included in the sample (number of regions included per country in brackets): Austria (9), Belgium (11), Bulgaria (6), Switzerland (7), Cyprus (1), Czech Republic (8), Germany (38), Denmark (5), Estonia (1), Greece (13), Spain (16), Finland (4), France (1), Croatia (2), Hungary (6), Island (1), Italy (21), Luxembourg (1), Latvia (1), Macedonia (1), Malta (1), the Netherlands (12), Norway (7), Poland (10), Portugal (5), Romania (8), Sweden (8), Slovenia (2), Slovakia (4), the United Kingdom (38) 
Figure 1. Regional employment rates (\%) in NUTS 2 regions in Europe in 2018

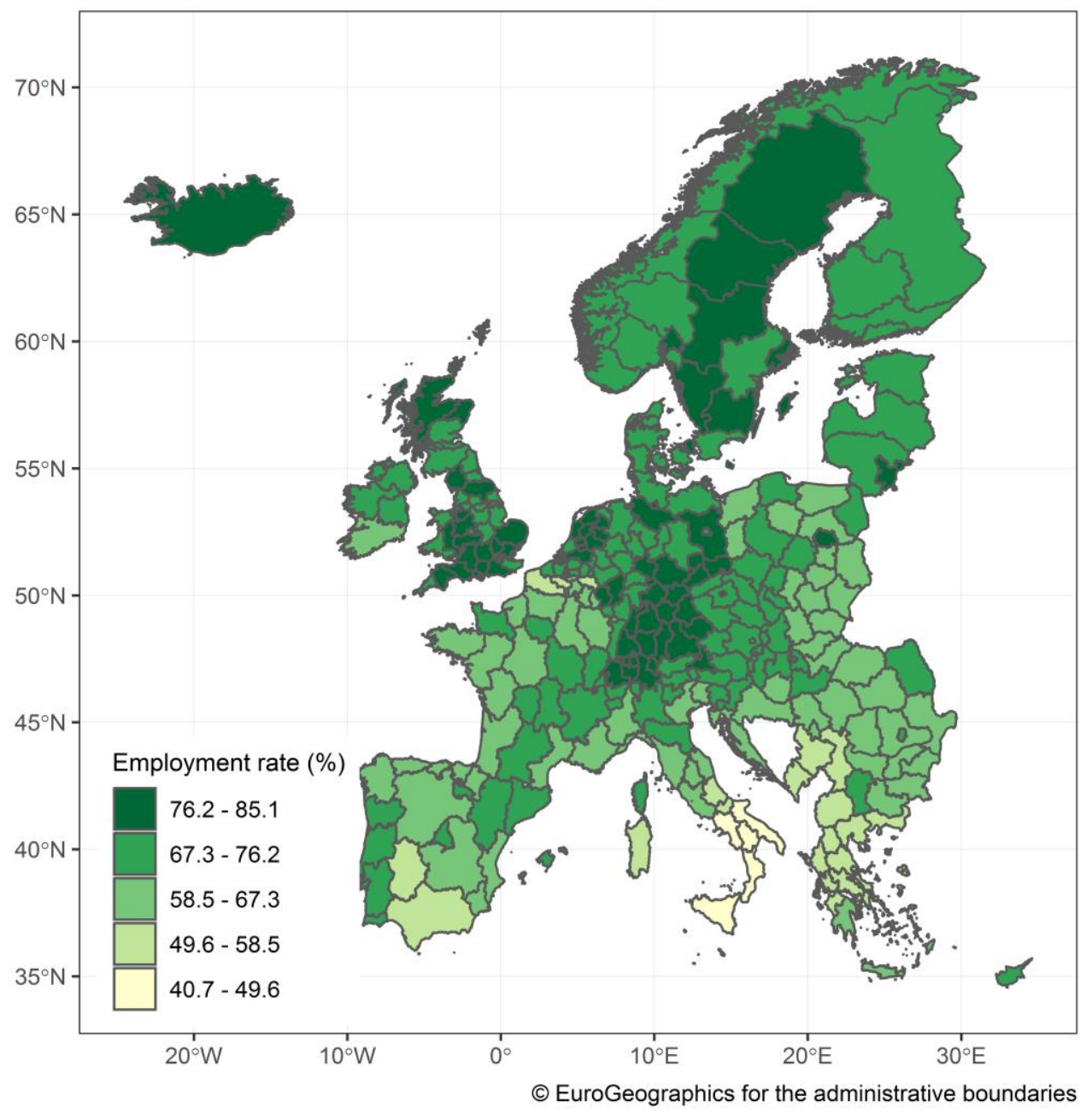

Source: Authors' representation based on Eurostat database (2020)

For a preliminary estimation of spatial interactions, the statistical indicator called Moran's I can be used (Moran, 1948). The estimated Moran's I for the employment rate in 2018 is 0.21 (z-value is 31.49). The positive sign of this indicator provides preliminary evidence that there are cooperation effects dominating between regional labour markets. The negative sign would have indicated that the competition for labour force between regions is stronger than the cooperation effects. However, Moran's I does not allow to control for the similarities in regional socio-economic and demographic characteristics, thus making it difficult to distinguish the spatial 
spillovers effect from that of common factors (see also Halleck Vega and Elhorst, 2016). To overcome these shortcomings, regression analysis is carried out by using different types of spatial econometric models.

The factors affecting unemployment and employment rate disparities at regional level are often grouped by the equilibrium and disequilibrium view introduced by Marston (1985) and applied by further studies, e.g. Aragon et al. (2003), Diaz (2016) and Semerikova (2015). The equilibrium view assumes that a high level of unemployment in the region is compensated by some other factors (higher wages, industry composition, amenities such as parks and rich cultural life). The disequilibrium view focuses on the adjustment procedure and on the factors affecting the speed of adjustment, such as age structure, skills and education level of the population, population density and structure of the housing market (see also extensive overview by Elhorst, 2003). Considering some limitations induced by shortage of regional data, this study uses controls for demographics, human capital, industry structure and country-level fixed effects (as country dummies).

Employment rate as a dependent variable $Y i$ is measured as the share of employed persons aged 15-64 in the region's $i$ population of the same age group (Table 1$)$. The explanatory variables $(X i)$, that can explain the differences in regional employment rates, are grouped into four categories characterizing the socioeconomic and demographic situation of the region $i$ : human capital, demographic composition, economic structure and country-specific conditions; the former group is expressed by country dummies.

\section{Table 1. Description of variables included in the regression models}

\begin{tabular}{ll}
\hline Variable & Description \\
\hline Employment rate & $\begin{array}{l}\text { Employed persons aged 15-64 as a percentage of the } \\
\text { population of the same age group. }\end{array}$ \\
\hline $\begin{array}{l}\text { Human capital: higher } \\
\text { education }\end{array}$ & $\begin{array}{l}\text { Share of population aged 25-64 who have successfully } \\
\text { completed tertiary studies (e.g. university, higher technical } \\
\text { institution, etc.). }\end{array}$ \\
\hline $\begin{array}{l}\text { Demographic composition: } \\
\text { youth }\end{array}$ & $\begin{array}{l}\text { Share of youth (aged 15-24) in the whole working age } \\
\text { population (aged 15-64). }\end{array}$ \\
\hline $\begin{array}{l}\text { Economic } \\
\text { manufacturing }\end{array}$ & Share of manufacturing in regional total employment. \\
\hline $\begin{array}{l}\text { Economic structure: services } \\
\text { Country-specific conditions: } \\
\text { country dummies }\end{array}$ & $\begin{array}{l}\text { Share of services in regional total employment. } \\
\text { cultural differences, institutions). }\end{array}$ \\
\hline
\end{tabular}

Source: Authors' representation

Regression models are specified and estimated following the main principles and steps of spatial econometrics. In a spatial econometric model, three different types of spatial interaction effects can be distinguished: endogenous interaction 
among the dependent variable ( $\mathrm{Y}$ ), exogenous interaction among the explanatory variables $(\mathrm{X})$ and interaction among the error terms $(\mathrm{u})$. Endogenous interaction effects result from direct interaction between regions and can be explained as part of an equilibrium outcome of a spatial interaction process. Endogenous interaction effects reflect the substantive form of spatial autocorrelation. Interaction effects restricted to error terms account for a nuisance form of spatial dependence.

The general specification of a spatial econometric model can be written as follows (Elhorst, 2014):

$$
\begin{gathered}
\boldsymbol{y}=\rho \boldsymbol{W} \boldsymbol{Y}+\alpha \boldsymbol{\iota}_{N}+\boldsymbol{X} \boldsymbol{\beta}+\boldsymbol{W} \boldsymbol{X} \boldsymbol{\theta}+\boldsymbol{\mu}+\boldsymbol{u} \\
\boldsymbol{u}=\lambda \boldsymbol{W} \boldsymbol{u}+\varepsilon
\end{gathered}
$$

where $\boldsymbol{y}$ is a $(N \times 1)$ vector of dependent variables, $\rho$ is the spatial autoregressive coefficient, $\boldsymbol{X}$ is a $(N \times k)$ matrix of k explanatory variables, $\boldsymbol{\theta}$ is a $(k \times 1)$ vector of parameters, $\boldsymbol{\iota}_{N}$ is a $(N \times 1)$ vector of ones, $\alpha$ is a constant term parameter, $\boldsymbol{\beta}$ is a $(k \times 1)$ vector of parameters, $\boldsymbol{\mu}$ is a $(N \times 1)$ vector of region-specific intercept variable, $\lambda$ is a scalar of the spatial autocorrelation coefficient, $\boldsymbol{W}$ is the $(N \times N)$ spatial weight matrix and random term $\varepsilon \sim N\left(0, \sigma^{2}\right)$.

In this study, the spatial error and spatial lag model, accounting for a different spatial interaction effect, are estimated ${ }^{3}$. The spatial lag model (SLM), also known as the spatial autoregressive model (SAR), accounts for the endogenous interaction effect (sets $\lambda=0$ and $\boldsymbol{\theta}=0$ in eq. (1) and (2)), and the spatial error model (SEM) accounts for the interaction effect in error terms (sets $\rho=0$ and $\boldsymbol{\theta}=0$ in eq. (1)); both are presented in the seminal book by Anselin (1988). Ignoring spatially lagged dependent variables may lead to biased and inefficient estimates; ignoring spatially correlated errors may result in inefficient estimates. In addition, the spatial autoregressive model with autoregressive disturbances (SARAR), which combines endogenous and error term interaction effects, is estimated. The Lagrange multiplier (LM) tests, presented by Anselin et al. (1996), are used to test for several types of interaction. The estimation of SEM, SLM and SARAR models allows to determine two different types of spatial interaction effects. First, this study identifies the substantive form of spatial autocorrelation (expressed by $\rho$ ), indicating that the employment rate in one region is directly affected by employment rate changes in other regions. Second, the nuisance form of spatial dependence (expressed by $\lambda$ ), which shows that employment rate in one region is affected by shocks in other regions, is also detected.

The estimation of spatial interaction indicators relies on using a spatial weight matrix $W$, which determines the structure and intensity of spatial dependence

${ }^{3}$ For more detailed information on the specified and implemented models, see also Kivi (2019). 
between regions. The choice of a spatial weight matrix is somewhat arbitrary, as the structure of spatial interactions is not known a priori. There are various ways to specify the spatial weights matrix and that may somewhat influence the estimation results.

In this paper, the distance-based matrix is used. The elements of the matrix are constructed as the inverse values of distances between the physical geographic centres of the regions. The spatial weight matrix is row-standardized for easier interpretation following the common practice of earlier empirical studies (e.g. Niebuhr, 2003; Semerikova, 2015). To study different types of spatial interactions in European regional labour markets and check for the resilience of the spatial interactions over time, several types of cross-section models for different years are estimated and discussed in the next part of the paper (OLS model, SLM, SEM and SARAR). The estimations rely on the Eurostat NUTS 2 level regions' data from the period 2004-2018.

\section{Empirical results: spatial interactions in European regional labour markets}

The estimation results of modelling regional employment rates and their possible spatial interactions are presented in Table 2. The LM-tests reject the null hypotheses of no spatial dependence in OLS model residuals and of no spatial lag dependence (the test statistics are $\mathrm{LM}_{\mathrm{e}}=15.96$ and $\mathrm{LM}_{1}=52.45$ respectively). That means there is a risk of obtaining biased and/or inefficient results if spatial interactions are not considered while analyzing regional employment in Europe. Thus, in order to analyse regional labour markets and to identify spatial interactions between the regions, it is necessary to implement spatial econometric methods.

Based on the information criteria (AIC, BIC), the most general SARAR model seems to be the preferred specification. The models that control for demographic structure, human capital, industrial composition and country-level fixed effects find the spatial autocorrelation coefficient $\lambda$ in the SEM model and the spatial autoregressive coefficient $\rho$ in the SLM model to be significant. In the case of SARAR, both autocorrelation coefficient $\lambda$ and autoregressive coefficient $\rho$ are statistically significant (Table 2 ). The estimated coefficients are rather similar across the models, confirming that the estimation results are robust. ${ }^{4}$ These results show that both substantive (measured by coefficient $\rho$ ) and nuisance (measured by coefficient $\lambda$ ) forms of spatial autocorrelation exist for regional employment rates. The former means that the employment rate in one region is directly affected by employment rate changes in other regions, while the latter shows that the employment rate in one region is affected by shocks in other regions.

\footnotetext{
${ }^{4}$ Panel data estimates of random effects over the period 2004-2018 also confirm that the estimated results are robust. These estimation results are available upon request.
} 
Table 2. Estimates of regional employment rate based on different types of models for European NUTS 2 level regions in 2018

\begin{tabular}{|c|c|c|c|c|}
\hline Employment & OLS & SEM & SLM & SARAR \\
\hline \multirow[t]{2}{*}{ Youth } & $-0.711 * *$ & $-0.726^{* *}$ & $-0.692 * *$ & $-0.711 * *$ \\
\hline & {$[0.192]$} & {$[0.175]$} & {$[0.165]$} & [0.164] \\
\hline \multirow[t]{2}{*}{ Services } & -0.047 & -0.071 & -0.083 & -0.101 \\
\hline & {$[0.071]$} & {$[0.063]$} & {$[0.060]$} & {$[0.060]$} \\
\hline \multirow[t]{2}{*}{ Manufacturing } & $0.232 * *$ & $0.181^{*}$ & $0.180 * *$ & $0.139 *$ \\
\hline & {$[0.077]$} & {$[0.070]$} & {$[0.066]$} & {$[0.065]$} \\
\hline \multirow[t]{2}{*}{ Higher education } & $0.233 * *$ & $0.247 * *$ & $0.235^{* *}$ & $0.252 * *$ \\
\hline & {$[0.054]$} & {$[0.050]$} & {$[0.046]$} & [0.047] \\
\hline \multirow[t]{2}{*}{ Constant } & $0.792 * *$ & $0.807 * *$ & 0.133 & $0.156^{*}$ \\
\hline & {$[0.070]$} & {$[0.068]$} & {$[0.071]$} & {$[0.078]$} \\
\hline \multirow[t]{2}{*}{$\lambda$} & & $0.907 * *$ & & $0.855^{* *}$ \\
\hline & & {$[0.094]$} & & {$[0.144]$} \\
\hline \multirow[t]{2}{*}{$\rho$} & & & $0.943 * *$ & $0.933 * *$ \\
\hline & & & {$[0.056]$} & {$[0.065]$} \\
\hline Country dummies & YES & YES & YES & YES \\
\hline AIC & -859.32 & -869.06 & -890.66 & -896.80 \\
\hline $\mathrm{BIC}$ & -739.86 & -742.57 & -764.17 & -766.81 \\
\hline $\mathrm{R}^{2}$ & 0.7914 & & & \\
\hline
\end{tabular}

Note: $*$ significant at 5\%; ** significant at $1 \%$. Standard errors are in brackets. $\mathrm{N}=248$. Dependent variable: employment rate.

Source: Authors' calculations based on Eurostat database (2020)

The results indicate that instead of competition for labour force between regions, which would result in negative dependence, cooperation effects dominate in European regional labour markets. Overall, the results point to the fact that there are spillovers across regional labour markets, which can be expressed, for example, in the form of workers' mobility from one region to another. While based on earlier studies (e.g. Mayor and López, 2008; Pavlyuk, 2011), positive spatial dependence could not be confirmed in terms of employment rates, our results give support to the existence of positive spatial interactions in case of employment. Our results are in line with the results of the empirical study by Lewis et al. (2011) on employment in the manufacturing sector of South Carolina. The results of Brada et al. (2021) on the spatial spillovers in the employment recovery after the financial crisis also support our findings. 
The estimation results show that differences in regional employment rates are explained by several socio-economic and demographic factors (see Table 2). The positive relationship between the regional employment rate and the share of higher educated people as a proxy for human capital reflect the fact that better educated people are in higher demand in regional labour markets and more flexible in terms of acquiring the new skills and knowledge required for different positions. As expected, good human capital is important for regional development. In regions with a higher proportion of young people, the employment rate is lower, on the average, as a significant part of the young people are involved in studies and are, therefore, out of the labour force. As a rule, the employment rate is higher in the regions where the manufacturing sector share is higher in regional employment. The composition of the services sector's labour market is very heterogeneous in European countries and regions. That can provide the explanation to the fact that the relationship between employment and the services sector share in regional employment is not statistically significant. As a rule, country dummies are statistically significant, indicating that country-level factors (e.g. differences in culture, institutions) play an important role in explaining regional disparities in employment.

\section{Figure 2. Spatial coefficients of employment rates for years 2004-2018}

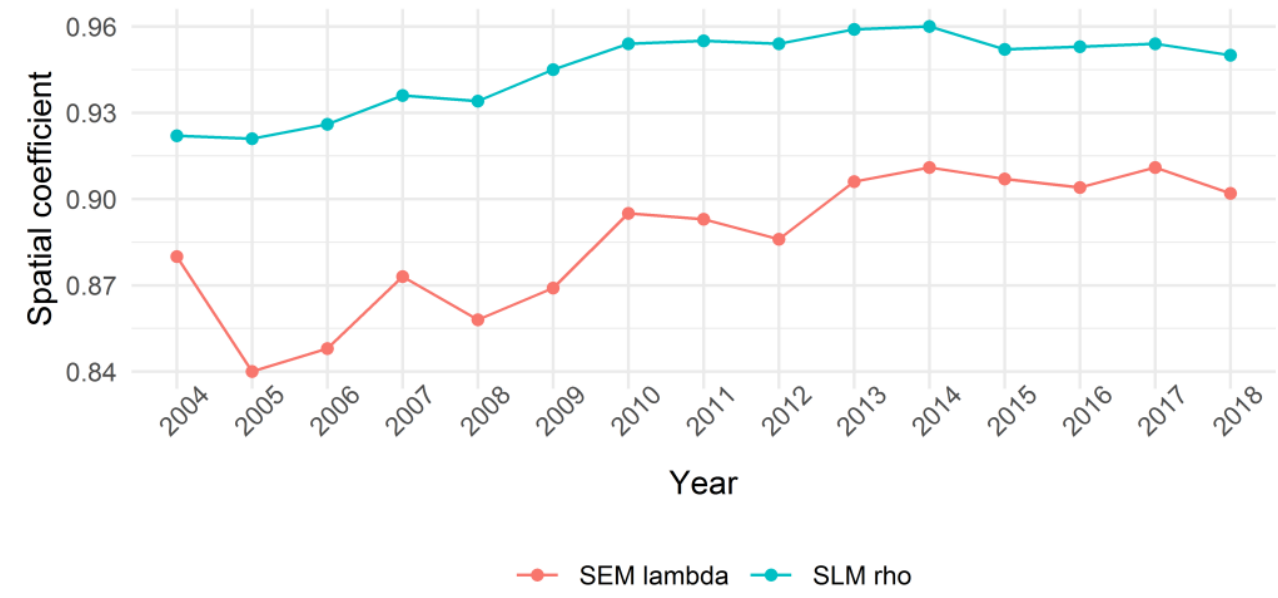

Note: the figure displays spatial coefficients estimated by using SEM and SLM models for each year; $\mathrm{N}=230$. Dependent variable: employment rate.

Source: Authors' calculations based on Eurostat database (2020)

Besides measuring the strength and type of spatial spillovers, the focus of this paper is on the dynamics of spatial interactions. To observe whether spatial interactions have increased over the years and consider their response to shocks, the 
spatial autocorrelation coefficient $\lambda$ from the SEM model and the spatial autoregressive coefficient $\rho$ from the SLM model are estimated for each year in the period of 2004-2018 (Figure2). The results show that the spatial coefficients of the estimated models slightly increased since the Eastward enlargement of the EU with the growth continuing until the year 2010 (see also Appendix 1). Positive spatial dependence is strong and cooperation effects also dominated during the 2008 financial crisis. The continuing growth of spatial coefficients over the financial crisis period indicates that the European labour markets are rather resilient to crisis in the sense of spatial interactions.

The overall moderate growth in spatial dependence and its stability in recent years is in line with the previous findings on a relatively slow growth in the labour market integration (measured in labour mobility) in the European Union (see e.g. Krause et al., 2017). Different factors that lessen the need to commute or migrate for work to neighbouring regions could presumably slow down the growth of the spatial dependence over the period. One of the reasons for that could be the enhanced possibilities for new working ways, including remote working. Another possible explanation is the convergence in average wages and overall living standards between the different European regions since the time of the Eastern enlargement of EU. Therefore, the gain from migrating and commuting for work has somewhat diminished. That also explains the evidence that spatial interactions are resilient to economic cycles and uncertainties.

\section{Conclusions}

This study explores spatial interactions by using NUTS 2 level regional data and implementing different types of spatial econometric models that consider spatial effects through a dependent variable and an error term. The estimation results are robust and stable over the models. The findings of this study emphasize the importance of spatial interactions in regional employment in Europe, which has to be considered in elaborating regional policy measures.

The findings show that regional labour markets in Europe cluster in space. Spatial interactions are found to be positive, indicating that cooperation effects between regions mainly dominate over competition for labour force. Both substantive and nuisance forms of spatial dependence exist. The employment rate in one region is not only directly affected by employment rate changes in other regions but also by unobserved shocks in other regions. The results indicate that spatial dependence between regional labour markets in Europe has slightly risen throughout the years starting from the Eastern enlargement of the European Union in 2004. During the previous financial crisis, a slight increase of spatial interactions in employment can be detected. Thus, European labour markets are rather resilient in the sense of spatial interactions and cooperation effects dominate across economic cycles. Despite the overall growing trend in spatial interactions, recent years show 
stability or even a slight tendency to decrease. This empirical evidence can be explained by changes in working ways (e.g. the increasing role of remote work), which lessen the need for labour force mobility.

The results of the study provide additional valuable information for the development of regional and labour market policy measures in Europe. Possible spatial interactions have to be seriously considered in elaborating strategic views as well as long and short-run plans of regional development. For example, enhancing infrastructure and transport connections between neighbouring regions could benefit several regions as it enables the mobility of labour force and, thereby, more efficient matching of workers to jobs based on their skills, thus ensuring better adaptation to increasing uncertainties, e.g. those raised by the COVID-19 pandemic. Planning processes should be conducted in close cooperation between regional governmental and business authorities relying on the results of a profound analysis of possible spatial interactions and effects.

Estimating the models based on NUTS 3 data would be a challenge for future research. Using the less aggregated data of NUTS 3 regions would enable researchers and policy makers to better capture spatial interactions between regions within and across countries, particularly in the case of small countries. The results of this study support the necessity to improve the system of the Eurostat regional dataset, thus allowing to remarkably improve the analysis of regional development and to elaborate effective policy measures considering the uncertainties raised by several types of crises.

Acknowledgements: The authors are grateful for the thoughtful suggestions and comments of the two anonymous reviewers. The research work was supported by the EEA and Norwegian Financial Mechanisms for 2014-2021 within the project "The economic integration of the Nordic-Baltic region through labour, innovation, investments and trade" [project number S-BMT-21-7; project acronym LIFT].

\section{References}

Anselin, L., Bera, A.K., Florax, R. and Yoon, M.J. (1996), Simple diagnostic tests for spatial dependence, Regional Science and Urban Economics, 26(1), pp. 77-104. https://doi.org/10.1016/0166-0462(95)02111-6

Anselin, L. (1988), Spatial Econometrics: Methods and Models, Dordrecht, Netherlands: Kluwer Academic Publishers.

Aragon, Y., Haughton, D., Haughton, J., Leconte, E., Malin, E., Ruiz-Gazen, A. and ThomasAgnan, C. (2003), Explaining the pattern of regional unemployment: The case of the Midi-Pyrénées region, Papers in Regional Science, 82(2), pp. 155-174. https://doi.org/10.1111/j.1435-5597.2003.tb00009.x 
Autant-Bernard, C. and LeSage, J.P. (2011), Quantifying Knowledge Spillovers Using Spatial Econometric Models, Journal of Regional Science, 51(3), pp. 471-496. https://doi.org/10.1111/j.1467-9787.2010.00705.x

Badinger, H. and Url, T. (2002), Determinants of regional unemployment: some evidence from Austria, Regional Studies, 36(9), pp. 977-988. https://doi.org/10.1080/0034340022000022558

Beyer, R.C.M. and Stemmer, M.A. (2016), Polarization or convergence? An analysis of regional unemployment disparities in Europe over time, Economic Modelling, 55, pp. 373-381. https://doi.org/10.1016/j.econmod.2016.02.027

Blanchard, O.J. and Katz, L.F. (1992), Regional evolutions, Brookings Papers on Economic Activity, 1, pp. 1-75.

Brada, Josef C., Gajewski, P. and Kutan, A.M. (2021), Economic resiliency and recovery, lessons from the financial crisis for the COVID-19 pandemic: A regional perspective from Central and Eastern Europe, International Review of Financial Analysis, 74(C), pp. 1-12. https://doi.org/10.1016/j.irfa.2021.101658

Cingano, F. and Rosolia, A. (2012), People I know: Job search and social networks, Journal of Labor Economics, 30(2), pp. 291-332. https://doi.org/10.1086/663357

Clark, J. and Bailey, D. (2018), Labour, work and regional resilience, Regional Studies, 52(6), pp. 741-744. https://doi.org/10.1080/00343404.2018.1448621

Cracolici, M.F., Cuffaro, M. and Nijkamp, P. (2007), Geographical distribution of unemployment: An analysis of provincial differences in Italy, Growth and Change, 38(4), pp. 649-670. https://doi.org/10.1111/j.1468-2257.2007.00391.x

Diaz, A.M. (2016), Spatial Unemployment Differentials in Colombia, Desarrollo y Sociedad, 76, pp. 123-163. https://doi.org/10.13043/DYS.76.3

Elhorst, J.P. (2003), The mystery of regional unemployment differentials: Theoretical and empirical explanations, Journal of Economic Surveys, 17(5), pp. 709-748. https://doi.org/10.1046/j.1467-6419.2003.00211.x

Elhorst, J.P. (2014), Spatial Econometrics: From Cross-sectional Data to Spatial Panels, Berlin: Springer. https://doi.org/10.1007/978-3-642-40340-8

European Commission (2020), NUTS background (retrieved from https://ec.europa.eu/eurostat/web/nuts/background).

Filiztekin, A. (2009), Regional unemployment in Turkey, Papers in Regional Science, 88(4), pp. 863-878. https://doi.org/10.1111/j.1435-5957.2009.00237.x

Halleck Vega, S. and Elhorst, J.P. (2014), Modelling regional labour market dynamics in space and time, Papers in Regional Science,93(4), pp. 819-841. https://doi.org/10.1111/pirs.12018

Halleck Vega, S. and Elhorst, J.P. (2016), A regional unemployment model simultaneously accounting for serial dynamics, spatial dependence and common factors, Regional Science Und Urban Economics, 60, pp. 85-95. https://doi.org/10.1016/j.regsciurbeco.2016.07.002 
Kivi, L.H. (2019), Spatial Interactions of Regional Labour Markets in Europe, Working paper No 119, School on Economics and Business Administration, University of Tartu, $38 \mathrm{p}$.

Kondo, K. (2015), Spatial persistence of Japanese unemployment rates, Japan and the World Economy, 36, pp. 113-122. https://doi.org/10.1016/j.japwor.2015.11.001

Krause, A., Rinne, U. and Zimmermann, K.F. (2017), European labor market integration: what the experts think, International Journal of Manpower, 38(7), pp. 954-974. https://doi.org/10.1108/IJM-05-2017-0101

Lewis, Jr. W., DiFurio, F. and Goode, T. (2011), Testing for the Presence of Spatial Dependence in Manufacturing Employment in South Carolina Counties, Southern Business \& Economic Journal, 34, pp. 41-53.

López-Bazo, E., Del Barrio, T. and Artis, M. (2002), The regional distribution of Spanish unemployment: A spatial analysis, Papers in Regional Science, 81(3), pp. 365-389. https://doi.org/10.1111/j.1435-5597.2002.tb01239.x

Marston, S.T. (1985), Two views of the geographic distribution of unemployment, Quarterly Journal of Economic, 100(1), pp. 57-79.

Mayor, M. and López, A.J. (2008), Spatial shift-share analysis versus spatial filtering: an application to Spanish employment data, Empirical Economics, 34, pp. 123-142. https://doi.org/10.1007/s00181-007-0167-9

Molho, I. (1995), Spatial autocorrelation in British unemployment, Journal of Regional Science, 35(4), pp. 641-658. https://doi.org/10.1111/j.1467-9787.1995.tb01297.x

Moran, P. (1948), The interpretation of statistical maps, Journal of the Royal Statistical Society. Series B, 10, pp. 243-251.

Niebuhr, A. (2003), Spatial interaction and regional unemployment in Europe, European Journal of Spatial Development, 5, pp. 1-26.

Patacchini, E. and Zenou, Y. (2007), Spatial dependence in local unemployment rates, Journal of Economic Geography, 7(2), pp. 169-191. https://doi.org/10.1093/jeg/lbm001

Pavlyuk, D. (2011), Spatial Analysis of Regional Employment Rates in Latvia, Sustainable Spatial Development, 2, pp. 56-62.

Semerikova, E. (2015), Spatial Patterns of German Labour Market: Panel Data Analysis of Regional Unemployment, in: Mussida, C. and Pastore, F. (eds.), Geographical Labour Market Imbalances: Recent Explanations and Cures, Berlin-Heidelberg, Germany: Springer, pp. 37-64. 


\section{Appendix}

Appendix 1. Spatial coefficients of employment rates for years 2004-2018

\begin{tabular}{|c|c|c|c|c|}
\hline \multirow[b]{2}{*}{ Year } & \multirow{2}{*}{$\begin{array}{c}\text { SEM } \\
\lambda\end{array}$} & \multirow{2}{*}{$\begin{array}{c}\text { SLM } \\
\rho\end{array}$} & \multicolumn{2}{|c|}{ SARAR } \\
\hline & & & $\rho$ & $\lambda$ \\
\hline 2004 & $0.880 * * *$ & $0.922 * * *$ & $0.908 * * *$ & $0.802 * * *$ \\
\hline 2005 & $0.840 * * *$ & $0.921 * * *$ & $0.909 * * *$ & 0.624 \\
\hline 2006 & $0.848^{* * *}$ & $0.926^{* * *}$ & $0.914 * * *$ & 0.640 \\
\hline 2007 & $0.873 * * *$ & $0.936 * * *$ & $0.925 * * *$ & $0.733^{*}$ \\
\hline 2008 & $0.858 * * *$ & $0.934 * * *$ & $0.923 * * *$ & 0.638 \\
\hline 2009 & $0.869 * * *$ & $0.945^{* * * *}$ & $0.936 * * *$ & 0.639 \\
\hline 2010 & $0.895^{* * *}$ & $0.954 * * *$ & $0.697 * *$ & $2.747 * * *$ \\
\hline 2011 & $0.893 * * *$ & $0.955 * * *$ & $0.948 * * *$ & $0.717^{*}$ \\
\hline 2012 & $0.886^{* * *}$ & $0.954 * * *$ & $0.946 * * *$ & 0.634 \\
\hline 2013 & $0.906 * * *$ & $0.959 * * *$ & $0.951 * * *$ & $0.760 * *$ \\
\hline 2014 & $0.911^{* * *}$ & $0.960 * * *$ & $0.952 * * *$ & $0.801 * * *$ \\
\hline 2015 & $0.907 * * *$ & $0.952 * * *$ & $0.941 * * *$ & $0.807 * * *$ \\
\hline 2016 & $0.904 * * *$ & $0.953 * * *$ & $0.943 * * *$ & $0.796^{* * *}$ \\
\hline 2017 & $0.911^{* * *}$ & $0.954 * * *$ & $0.944 * * *$ & $0.823 * * *$ \\
\hline 2018 & $0.902 * * *$ & $0.950 * * *$ & $0.940 * * *$ & $0.802 * * *$ \\
\hline
\end{tabular}

Note: * significant at $10 \%$; ** significant at 5\%; *** significant at $1 \%$. The Table displays spatial coefficients estimated by using SEM, SLM and SARAR models for each year; $\mathrm{N}=230$. Dependent variable: employment rate.

Source: Authors' calculations based on Eurostat database (2020) 